Meta

Journal des traducteurs

Translators' Journal

\title{
Use of the Semantic Differential in Bilingualism Research and its Relevance to Translation
}

\section{David Romney et John Bynner}

Volume 26, numéro 3, septembre 1981

URI : https://id.erudit.org/iderudit/003977ar

DOI : https://doi.org/10.7202/003977ar

Aller au sommaire du numéro

\section{Éditeur(s)}

Les Presses de l'Université de Montréal

ISSN

0026-0452 (imprimé)

1492-1421 (numérique)

Découvrir la revue

Citer cet article

Romney, D. \& Bynner, J. (1981). Use of the Semantic Differential in Bilingualism Research and its Relevance to Translation. Meta, 26(3), 229-243.

https://doi.org/10.7202/003977ar

\section{Résumé de l'article}

To investigate bilingual subjects' perceptions of the connotative differences between concepts in English and French, a form of the semantic differential was employed in which the scales were derived from Cattell's 16 personality factors. Altogether 16 concepts were rated and these were made up of four sets, each set containing a pair of synonyms in English and a pair of synonyms (their translation-equivalents) in French. Even though the sets themselves were easily distinguishable in terms of their affective meaning, no significant differences in affective meaning emerged between the concepts in any of the sets either within or across languages. There were, however, significant differences between individuals in the ways they perceived the concepts. Some of these differences seemed to be due to the effects of dominant language, A cluster analysis of the individuals in terms of the semantic difference between concepts and their translation-equivalents (over and above the difference between synonyms) gave little support to the postulated distinction between the two types of bilingual, compound and coordinate, although there was some evidence that the compound bilingual exists as a separate type. 


\title{
Use of the Semantic Differential in Bilingualism Research and its Relevance to Translation
}

\author{
DAVID ROMNEY and JOHN BYNNER
}

\begin{abstract}
To investigate bilingual subjects' perceptions of the connotative differences between concepts in English and French, a form of the semantic differential was employed in which the scales were derived from Cattell's 16 personality factors. Altogether 16 concepts were rated and these were made up of four sets, each set containing a pair of synonyms in English and a pair of synonyms (their translation-equivalents) in French. Even though the sets themselves were easily distinguishable in terms of their affective meaning, no significant differences in affective meaning emerged between the concepts in any of the sets either within or across languages. There were, however, significant differences between individuals in the ways they perceived the concepts. Some of these differences seemed to be due to the effects of dominant language. A cluster analysis of the individuals in terms of the semantic difference between concepts and their translation-equivalents (over and above the difference between synonyms) gave little support to the postulated distinction between the two types of bilingual, compound and coordinate, although there was some evidence that the compound bilingual exists as a separate type.
\end{abstract}

\section{USE OF THE SEMANTIC DIFFERENTIAL IN BILINGUALISM RESEARCH AND ITS RELEVANCE TO TRANSLATION ${ }^{1}$}

In studies of translation, there has been increasing interest in recent years in the "affective" differences in the meanings of words between different language cultures. However successful a translator is in conveying the "denotative" meaning of a word from one language to another, i.e., its "literal" aspects as encapsulated in the dictionary definition, he will never be able to convey entirely those connotative or affective features which can be fully appreciated only through full immersion in a language culture over a long period of time. Such features include all the nuances of the word built up by the associations it has gathered in the culture as exemplified in its use in metaphor.

The distinction between "affective" and "denotative" meanings of words rellates to a postulated difference between two types of bilingual: the "compound" and "coordinate" (Erwin and Osgood, 1954). The true compound bilingual learns and uses the two languages, almost interchangeably, in the same sociocultural context whereas the true coordinate bilingual acquires and uses the two languages in separate contexts. It has been proposed that the compound bilingual would have much less difficulty than the coordinate bilingual in translating from one language to another because he is less sensitive than the coordinate bilingual to the affective aspects of words which can interfere with

1. This research was facilitated by Laurentian University professors Michael Dewson and Roger Pitblado whose help in using the university computer we gratefully acknowledge. 
"literal" translation (Lambert, Havelka and Crosby, 1958). However, the concept of compound versus coordinate bilingualism has been cogently attacked, for instance, by Diller (1970). To quote Diller :

I argue that it is an error to think that there are two kinds of bilingualism that fit the labels compound and coordinate. First, compound and coordinate bilingualism are poorly defined; second, the experimental evidence does not support these concepts; and third, there are strong linguistic reasons why these concepts cannot stand.

Regardless of the validity of the compound/coordinate distinction, the role of affective meaning in translation is of considerable interest in its own right. What are the major dimensions of the connotative distinctions between words and how do such distinctions differ between languages? Bilingual individuals are ideal subjects for investigating these questions empirically because unlike the monolingual who would have to be matched with another monolingual in the other language, the bilingual can act as his own control. Through the pioneering work of Osgood, Suci and Tannenbaum (1957) in the development of the semantic differential, there is also a ready-made methodology available for the investigation of affective meaning. In this approach, concepts such as single words (house, me, etc.) are rated on a set of bipolar scales representing different connotative aspects of their meaning (hot-cold, hard-soft, etc.). From the analysis of large numbers of such ratings over large numbers of concepts, Osgood and his associates were able to identify their well-known major dimensions of connotative meaning - Evaluation, Toughness, Potency - which have subsequently been replicated across many different languages (Miron and Osgood, 1969; Kuusinen, 1969; Tanaka, 1967).

In the study by Lambert et al. (1958), the OSD was used to rate common concepts and their French translations. (The latter were rated on Osgood's scales translated into French.) The average degree of differente between the French and English semantic ratings for the pairs of concepts was determined for each subject using Osgood's D score - the larger the D score, the greater the semantic differences between translation-equivalents in English and French. A similar study was carried out by Earle (1967) on subjects who were bilingual in English and Cantonese and another one by Stafford and Van Keuren (1969) on subjects bilingual in English and Navaho. However, the scales devised by Osgood for the original version of the Semantic Differential entail the use of a large and heterogeneous set of concepts if the major dimensions of affective meaning are to emerge free of distortions from their denotative characteristics. In studies using only a small number of concepts in a fairly homogeneous concept domain "concept scale interaction" is likely to present problems in analyzing the results (Bynner and Coxhead, 1979). Accordingly, rather than attempt to replicate the EPA dimensions identified by Osgood, which in any event may have little validity for restricted samples of concepts, there are advantage in choosing scales to represent typical ways in which the concepts are perceived. In the studies by McKennell and Bynner (1969) and Romney and Bynner (1972), for example, the dimensions sought, though clearly related to EPA, are labelled more specifically in terms of the scales' content. 
Another problem with the Lambert and similar studies is that the authors ignored the possibility that affective differences between translation-equivalents had no bearing on the languages in which the equivalents were expressed. Equivalent concepts in the same language even, i.e., synonyms, may have different connotative meanings. In order to assess affective differences between languages over and above any such differences that exist for synonyms within each language, synonyms and their translation-equivalents in both languages should have been used.

Although, as we have noted, there has been some limited application of the semantic differential in the study of bilingualism, it has never been used to find out precisely how the connotative distinctions between words across different languages are perceived by bilingual individuals using synonyms as controls; nor has there been any study, for example, of the role of such biographically defined characteristics as sex and dominant language in the bilingual's perceptions. This study represents a limited exploration of some of these issues which it is hoped will pave the way for more extensive investigations in the future.

\section{METHOD}

Our first step was to make a search for suitable "sets" of words, i.e., pairs of synonyms in English and French having the same dictionary definition in both languages, which might be expected to differ from each other connotatively (Chambers Twentieth Century Dictionary, 1977; Robert, 1977). This was no mean task! The words eventually chosen all designated types of people : sailor, mariner, matelot, marin; doctor, physician, docteur, médecin; miser, skinflint avare, pingre; monarch, sovereign, monarque, souverain. The number of words was limited to 16 in order not to make the task too burdensome for the subjects. The order of presentation of the words was arranged to ensure that words within the same set were not close together.

We have already mentioned the considerations that led us to seek a set of scales which, while still connotative in form, would relate clearly to the particular concepts under investigation, viz., types of people. The 16 major dimensions measured by Cattell, Eber and Taksuoka (1970) in their 16PF questionnaire have been extensively used in the study of interpersonal perception (e.g., Hallworth, 1965). They were ideally suited for the investigation of connotative distinctions between person synonyms of the kind employed in this study. Here the 16 Cattell scales were presented in the seven point bipolar format. The adjectives defining the scales were in English for the English concepts and in the published French version for the French concepts. In the 16PF, every scale is defined by a cluster of adjectives at each end. So as not to confuse the subject and reduce his spontaneity and speed of his responses, only one adjective was picked out of the cluster, i.e., the key adjective (marked in majuscules on the 16PF profile record sheet).

In addition to rating 16 concepts on the 16 scales, each subject was asked to fill in a short questionnaire to determine when and how they acquired their languages and where or in what circumstances they tended to use them in their everyday environment. This information was collected to that we could find out 
if the bilingual was basically an anglophone bilingual or a francophone bilingual. The dominant language was regarded as the one the individual felt most at home in. It was generally his mother tongue, the language he spoke most often, and the language he counted in.

Altogether 16 subjects were willing to cooperate, some in Canada, some in England. Their ages ranged from 26 to 58, the mean being 41 . Ten of them were university professors, three were schoolteachers, one was a university administrator, one was a nurse, and one was a secretary. With the exception of the schoolteachers, all the subjects were known personally and their bilingualism could be vouched for. The teachers were considered to be bilingual by the principal of their school. For nine, French was their first and dominant language; the remaining seven were anglophone bilinguals. Five of the francophone bilinguals and one of the anglophone bilinguals were females.

\section{ANALYSIS AND RESULTS}

The 16 rating scales were intercorrelated and the resultant matrix was factor analyzed. For the purpose of this analysis, each subject was counted 16 times, once for each concept. This "stringing-out" procedure was introduced by Osgood, and though there are problems in using it (Bynner and Coxhead, 1979), it is the one method that permits direct comparison between individuals and between concepts in the same "semantic space". The factor analysis - a principal factor analysis with iteration - produced four factors within eigenvalues higher than unity. But as there was a sharp drop in the eigenvalues after the first two factors and they accounted for $85 \%$ of the variance common to these four factors, it was decided that these two alone should be rotated. The rotated varimax factor loadings of the 16 scales for these two factors are given in Table 1. Only those scales with loadings which were relatively high (above .5) on one or other factor were used to define the factors.

Table 1

Factor Loadings on First Two (Rotated) Factors

\begin{tabular}{lrc}
\hline & Factor I & Factor II \\
\hline Outgoing & 81 & 02 \\
Intelligent & 15 & 50 \\
Emotionally stable & -04 & $7 I$ \\
Assertive & -22 & 02 \\
Happy-go-lucky & 59 & -42 \\
Conscientious & 11 & 69 \\
Venturesome & 81 & -05 \\
Tender-minded & 64 & 26 \\
Suspicious & -71 & -50 \\
Imaginative & 40 & -18 \\
Shrewd & -55 & -21 \\
Apprehensive & -59 & -42 \\
Experimenting & 63 & -03 \\
Self-sufficient & -24 & -00 \\
Controlled & -14 & 59 \\
Tense & -80 & -30
\end{tabular}

Note. Decimal points omitted. The loadings in italics correspond to the scales which were used to define each factor. 
Factor I is defined by the scales outgoing, venturesome, relaxed and experimenting; and factor II by the scales emotionally stable, conscientious and controlled. Although these factors are not identical to those defined by Cattell, there is sufficient similarity to warrant giving them the labels he uses for his second-order factors, viz., Extroversion and Anxiety (Pawick and Cattell, 1964) or alternatively to label them Introversion-Extraversion and Stability-Neuroticism which are the terms used to describe the two major ways personality is said to differ in Eysenck's personality theory (Eysenck and Eysenck, 1970).

Factor scores for each individual on each concept were also computed. These scores were then aggregated for each concept on each of the two factors so that between concept comparisons would be made (Table 2).

Table 2

Mean Factor Scores and Standard Deviations of Each Concept on the Two Factors

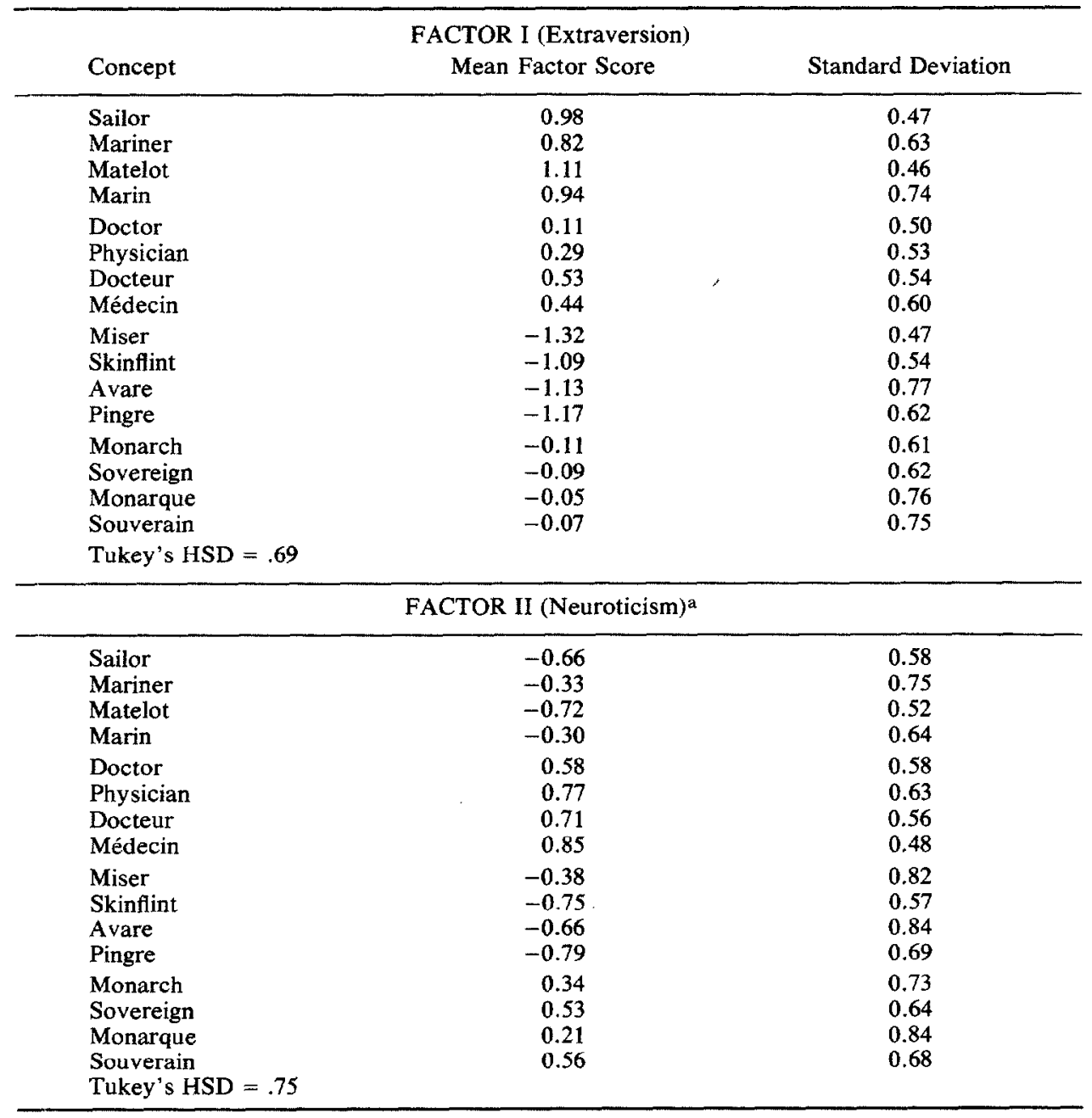

Neuroticism is at negative end of dimension. 
An analysis was then performed on each of the four sets of concepts simultaneously to ascertain whether the concepts inside a set were significantly different from each other on either of the factors. The results of the analysis are given in Table 3.

Table 3

ANOVA Repeated Measures of Concept Factor Scores for Each Concept Set

\begin{tabular}{lcrll}
\hline & \multicolumn{2}{c}{ Extraversion Scores } & & \\
Source of Variation & SS & df & MS & F \\
\hline Between concepts (A) & .0053 & 15 & .0004 & \\
Between concepts in a set (B) & .0045 & 3 & .0015 & .15 \\
Within concepts in a set & .4651 & 45 & .0103 & $66.27^{*}$ \\
Between sets of concepts (C) & 3.0492 & 3 & 1.0164 & \\
Within sets of concepts & .6902 & 45 & .0153 & \\
B $\times$ C & 3.6214 & 9 & .4024 & \\
A $\times$ B $\times$ C & .3464 & 135 & .0026 & \\
Total & 8.1821 & $255^{\text {a }}$ & & .23 \\
\hline & Neuroticism Scores & & \\
Between concepts (A) & .3148 & 15 & .0210 & \\
Between concepts in a set (B) & .0027 & 3 & .0009 & \\
Within concepts in a set & .1712 & 45 & .0038 & $.74 *$ \\
Between sets of concepts (C) & .5173 & 3 & .1724 & \\
Within sets of concepts & .6610 & 45 & .0147 & \\
B $\times$ C & .9900 & 9 & .1100 & \\
A $\times$ B $\times$ C & .4785 & 135 & .0035 & \\
Total & 3.1355 & $255^{\text {a }}$ & & \\
\hline
\end{tabular}

$* \mathrm{p}<.01$

a Two people who failed to rate the concept "pingre" were given an average score for this concept in this analysis.

The differences between concepts within any of the sets of four were not significant on either factor, irrespective of whether these concepts were drawn from the same language or from different languages. This finding casts doubt on our hypothesis that there would be differences in affective meaning at least across languages. On the other hand, as we might expect, the sets of concepts themselves were significantly different from each other on both factors. In other words, the intention of the research design to select sets of concepts which would be distinguishable from each in connotative meaning was achieved. When plotted in two-dimensional semantic space, each set of concepts is found to occupy a different quadrant. 


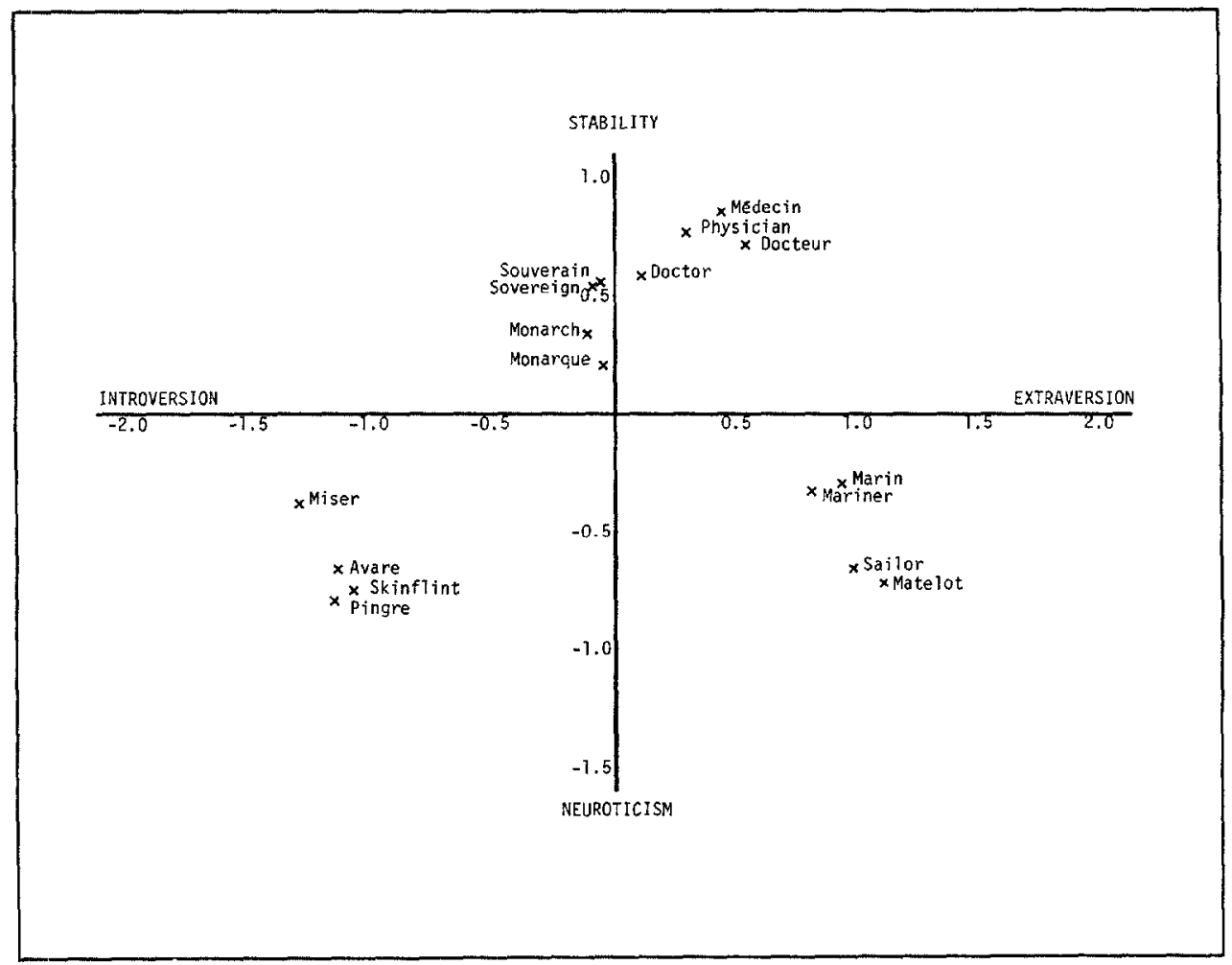

Figure 1. Concepts plotted on extraversion and neuroticism

The sailor set is perceived as extraverted and emotionally unstable, the doctor set as extraverted and stable, the miser set as introverted and unstable, and the monarch set as ambiverted and stable. These perceptions are of course those of the sample as a whole; inspection of individual factor scores, however, revealed marked individual differences. This led us to conduct a further analysis of variance in order to assess the overall differences between individuals. Although not highly significant, individual differences could be established, i.e., individuals were shown to differ in the connotative meaning they attributed to the different concepts. 
Table 4

ANOVA Repeated Measures of Concept Factor Scores Between Individuals and Between Concepts

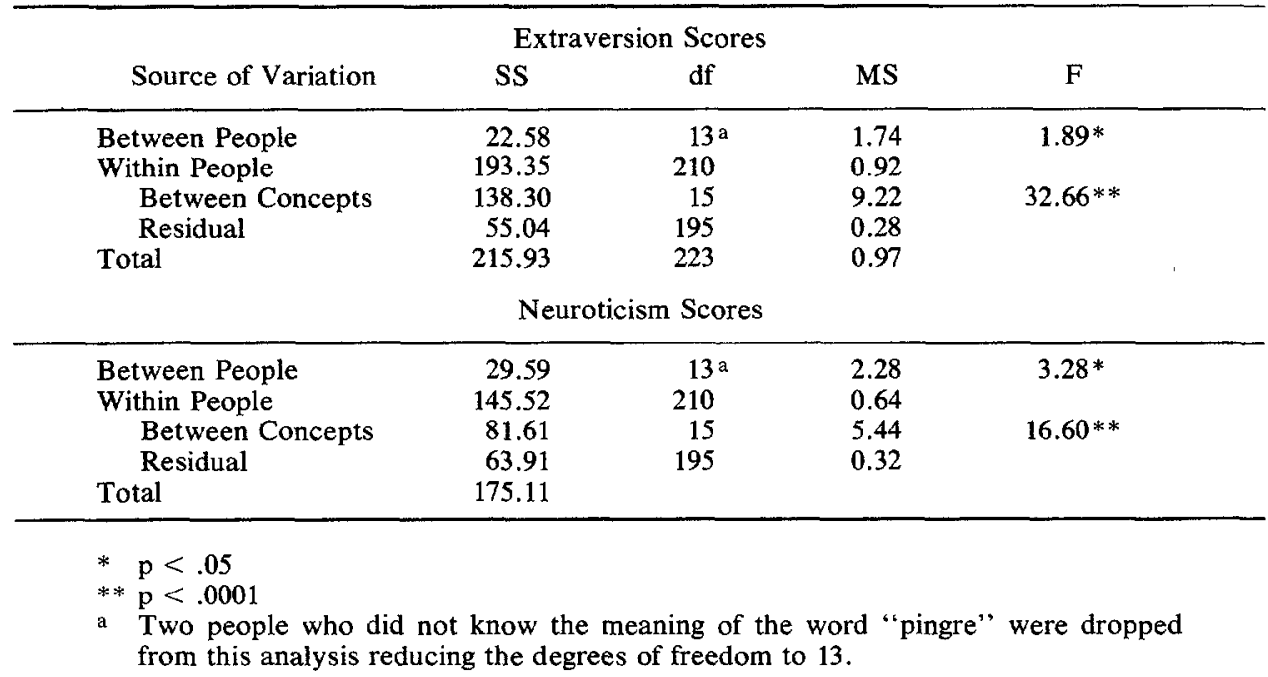

To explore this finding further, the concepts were plotted separately on the two dimensions for each individual. On scrutinizing these graphs, it appeared that some people perceived certain concept sets differently from others, and that this difference might be related to their dominant language. Moreover, we observed that for some people, concepts in a set were far apart (seemingly more apparent in males) and for others the concepts were tightly knit (seemingly more apparent in females). Figure 2 provides a good example of this, and also shows how two individuals perceive the same concepts quite differently. 


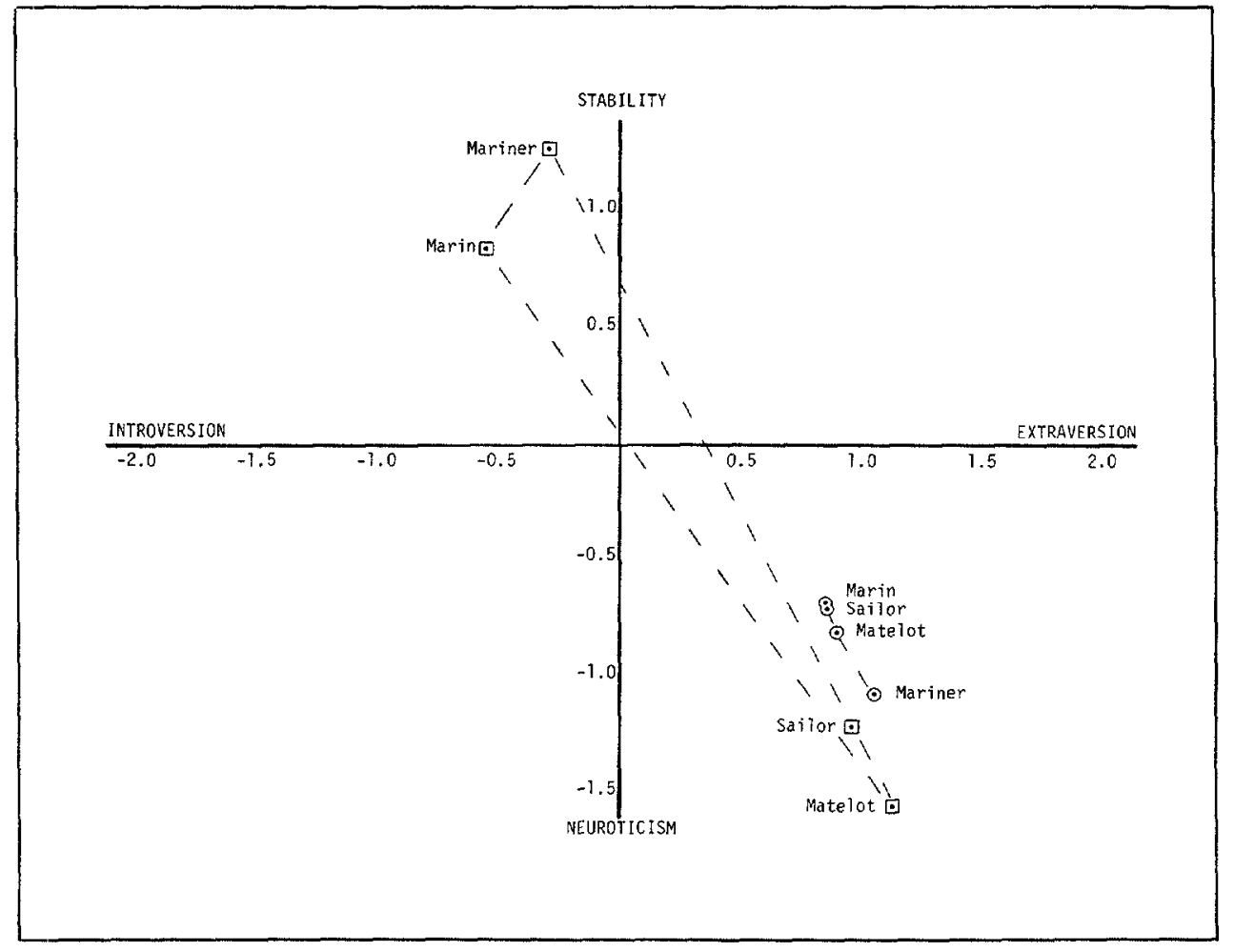

Figure 2. Individual differences in the configuration of a concept set

The next step was to test if the variance of these individual differences was in fact due to the effects of such biographical characteristics as dominant language or sex. Do anglophone bilinguals differ in their perceptions of the concepts from francophone bilinguals? Do men perceive the concepts differently from women? To investigate these possibilities, a further series of variance analyses was carried out. Differences were tested both at the level of single concepts (ANOVA) and for each concept set (MANOVA). For the latter analyses, the dependent variable was the vector of means for the set treated as a single variable. The results are shown in Table 5 . 
Table 5

Analysis of Variance of Language Type and Sex Differences for Each Concept Singly and in Concept Sets

\begin{tabular}{|c|c|c|c|c|c|c|c|c|}
\hline \multirow{3}{*}{ Concept } & \multicolumn{7}{|c|}{ EXTRAVERSION } & \multirow{3}{*}{$\begin{array}{l}\text { ANOVA } \\
\text { Sig. }\end{array}$} \\
\hline & \multicolumn{2}{|c|}{ Means } & \multirow{2}{*}{$\begin{array}{l}\text { MANOVA } \\
\text { Sig. }\end{array}$} & \multirow{2}{*}{$\begin{array}{l}\text { ANOVA } \\
\text { Sig. }\end{array}$} & \multicolumn{2}{|c|}{ Means } & \multirow{2}{*}{$\begin{array}{c}\text { MANOVA } \\
\text { Sig. }\end{array}$} & \\
\hline & Anglo & Franco & & & Male & Female & & \\
\hline Sailor & 1.06 & 0.90 & & & 0.89 & 1.11 & & \\
\hline Mariner & 0.72 & 0.78 & & & 0.61 & 1.00 & & \\
\hline Matelot & 1.13 & 1.02 & & & 1.03 & 1.13 & & \\
\hline Marin & 1.21 & 0.65 & & & 0.81 & 1.06 & & \\
\hline Doctor & 0.12 & 0.04 & & & 0.12 & -0.00 & & \\
\hline Physician & 0.29 & 0.22 & & & 0.27 & 0.22 & & \\
\hline Docteur & 0.48 & 0.49 & & & 0.46 & 0.53 & & \\
\hline Médecin & 0.47 & 0.33 & & & 0.34 & 0.48 & & \\
\hline Miser & -1.61 & -1.09 & & $* *$ & -1.35 & -1.26 & & \\
\hline Skinflint & -1.28 & -0.94 & ** & & -1.11 & -1.06 & & \\
\hline Avare & -1.31 & -0.99 & & & -1.21 & -1.03 & & \\
\hline Pingre & -1.38 & $-1.01 J$ & & & -1.29 & -1.01 & & \\
\hline Monarch & -0.07 & -0.13 & & & -0.06 & -0.18 & & \\
\hline Sovereign & -0.15 & -0.06 & & & -0.13 & -0.06 & & \\
\hline Monarque & -0.12 & -0.06 & & & -0.09 & -0.07 & & \\
\hline Souverain & -0.03 & -0.12 & & & -0.19 & -0.09 & & \\
\hline \multicolumn{9}{|c|}{ NEUROTICISM } \\
\hline Sailor & -0.79 & -0.39 & & & -0.61 & -0.49 & & \\
\hline Mariner & -0.48 & -0.13 & & & -0.29 & -0.27 & & \\
\hline Matelot & -0.73 & -0.45 & & & -0.57 & -0.57 & & \\
\hline Marin & -0.55 & -0.01 & & * & -0.23 & -0.27 & & \\
\hline Doctor & 0.84 & 0.52 & & & 0.71 & 0.58 & & \\
\hline Physician & 1.04 & 0.58 & & & 0.97 & 0.46 & & \\
\hline Docteur & 0.88 & 0.67 & & & 0.70 & 0.87 & & \\
\hline Médecin & 1.11 & 0.71 & & * & 0.91 & 0.83 & & \\
\hline Miser & -0.25 & -0.47 & & & -0.35 & -0.42 & & \\
\hline Skinflint & -0.76 & -0.74 & & & -0.79 & -0.69 & & \\
\hline Avare & -0.59 & -0.71 & & & -0.63 & -0.70 & & \\
\hline Pingre & -0.76 & -0.74 & & & -0.79 & -0.69 & & \\
\hline Monarch & 0.39 & 0.03 & & & 0.06 & 0.40 & & \\
\hline Sovereign & 0.83 & -0.01 & ** & $* *$ & 0.31 & 0.44 & & \\
\hline Monarque & 0.54 & -0.28 & & ** & 0.00 & 0.15 & & \\
\hline Souverain & 0.98 & -0.06 & & ** & 0.39 & 0.40 & & \\
\hline
\end{tabular}

$* \mathrm{p}<.10$

$* * \mathrm{p}<.05$

Although there were no overall differences between dominant language types or between sexes for the mean $\mathrm{E}$ and $\mathrm{N}$ scores across all concepts, for particular concept sets and for particular concepts within these sets there were differences between anglophones and francophones in the way the monarch set was perceived on Neuroticism and in the way the miser set was perceived on Extraversion.

With respect to the controversial coordinate/compound distinction discussed in the introduction, it was decided to investigate by means of cluster analysis whether any basis could be found for such a typology empirically. First of all, we needed to compute a score which would represent the kind of manifest 
distinction in perceptions between the two types of bilinguals proposed by such writers as Lambert et al. (1958), i.e., greater sensitivity on the part of coordinate bilinguals to connotative differences between translation-equivalents. Accordingly, a score for each factor was constructed for each set of concepts on the squared average difference between translation-equivalents minus the squared average difference between synonyms (see Appendix). Each set of concepts yielded two such scores, one for each factor. Cluster analysis was performed for each concept set taken separately and then for all of them simultaneously i.e., for the eight-dimensional space defined by the four concept sets and two factors. The clustering criterion used in each case was average distance within clusters based on (squared) Euclidian distances between individuals (Cormack, 1971; Sneath and Sokal, 1973).

Much the same result was obtained in each analysis. Approximately the same set of individuals was identified showing minimum perceived differences between concepts across languages (Table 6); there was no consistent clustering among the other individuals, i.e., no evidence that a group of individuals existed showing consistently large perceived differences between concepts across languages. Figure 3 shows by means of a phenogram the form of this clustering across all the concept sets treated simultaneously.

Table 6

Individuals Showing the Strongest Clustering in Terms of Translation-equivalent Differences on $E$ and $N$ for Each Concept Set

\begin{tabular}{ccccc}
$\begin{array}{c}\text { Sailor } \\
\text { Set }\end{array}$ & $\begin{array}{c}\text { Doctor } \\
\text { Set }\end{array}$ & $\begin{array}{c}\text { Miser } \\
\text { Set }\end{array}$ & $\begin{array}{c}\text { Monarch } \\
\text { Set }\end{array}$ & $\begin{array}{c}\text { Across } \\
\text { Concept } \\
\text { Sets }\end{array}$ \\
\hline 2 & 3 & 2 & 2 & $2(3)$ \\
12 & 5 & 11 & 4 & $9(4)$ \\
13 & 6 & 7 & 6 & $7(4)$ \\
5 & 7 & 13 & 11 & $5(2)$ \\
9 & 16 & 8 & 7 & $13(3)$ \\
6 & 9 & 9 & 9 & $16(3)$ \\
15 & 13 & & 10 & $8(2)$ \\
16 & 4 & & & $11(2)$ \\
10 & & & & 8 \\
8 & & & & $10(2)$ \\
\hline
\end{tabular}

Note. Numbers in brackets in the last column are the number of times the individual occurred in the clusters for the separate concept sets. 


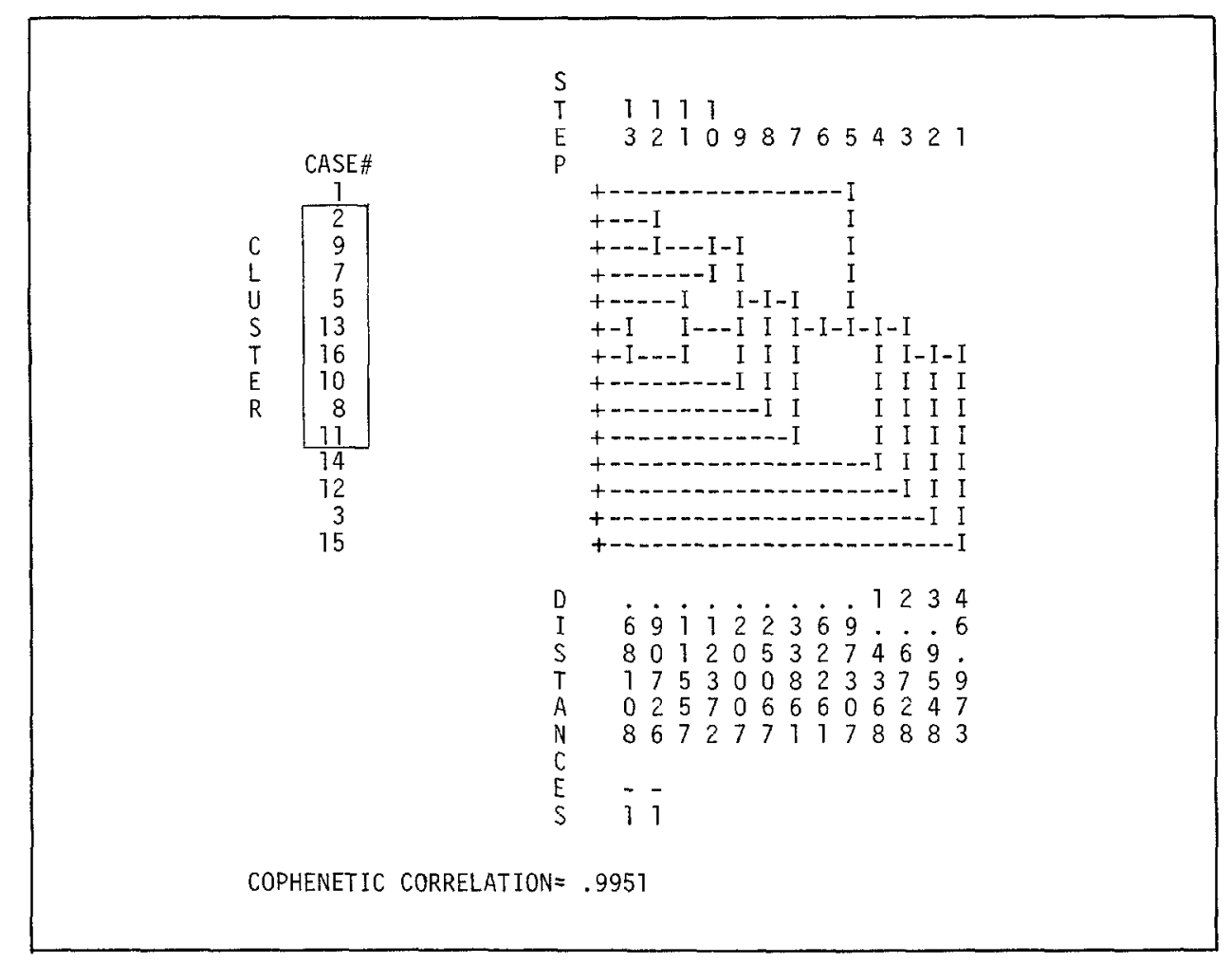

Figure 3. Cluster analysis across all concept sets

The main distinction here is between those individuals who see barely any connotative differences across languages (over and above differences within) and those who do see differences but for certain concepts only. We might loosely describe the former group as compound bilinguals; but there is no evidence of any other grouping corresponding to coordinate bilinguals ${ }^{2}$.

\section{DISCUSSION AND CONCLUSIONS}

Although we can hardly claim from these results to have resolved any of the major issues in the study of bilingualism, our novel approach in methodology and analysis has illuminated some of its aspects in a number of important ways. First, the sensitivity of the SD technique was demonstrated in the gross connotative differences that were revealed between the four concept sets. And while we were unable to establish statistically significant differences between concepts and their translation-equivalents, there were, however, individual differences which in the case of the monarch set in particular, could be attributed to the subject's dominant language. That is to say, although neither men and women

2. Virtually the same grouping cropped up whatever criteria for clustering were used. 
nor anglophones and francophones differed generally in their perceptions of most of the concepts, the francophones held a more negative perception of the monarch than did the anglophones, viewing the monarch as being more "unstable"'.

Perhaps the most interesting finding relating to individual differences arose from the cluster analysis. The conclusion from this analysis is that the connotative distinctions individuals perceive between translation-equivalents and between synonyms is very much individually based. The only grouping of individuals to appear corresponds roughly to the "compound" definition, i.e., the analysis separated the individuals who see little connotative difference across languages from the rest. It seems that for the rest of the individuals, although perceived differences across languages do discriminate between them, these differences relate to particular concepts and there is no general tendency for those perceiving the biggest differences to form a coherent group.

These conclusions are of course based upon limited data derived from a small sample of individuals who can in no way be considered representative of the population. In fact, it could be argued that there were no true coordinate bilinguals in the sample so that none could be identified through our analysis. There is obviously a need for extensive replication using different samples of people and different sets of concepts and different scales. Only then could we place complete confidence in the statistical analyses reported here. Our study, however, is fairly typical of studies employing the OSD technique with large numbers of concepts where the monotony and time-consuming nature of the task tends to discourage people from completing it. Typically, the problem is overcome by having students as subjects, and we can claim that at least in this study a group with reasonably mixed bilingual experience and occupational background in Canada and the United Kingdom was investigated. Nevertheless, the results of the statistical analyses should be treated cautiously and should be viewed more as descriptive of a given group of individuals pointing the way to further investigations rather than in any sense a test of a particular hypothesis (see Kish, 1959). For these reasons, we place more value on the cluster analysis which, making no claim to statistical inferences, enabled us to detect a naturally occurring group within the sample.

The results of our study suggest that although the bilingual does not necessarily discriminate in the affective or connotative sense between a word in one language and its translation-equivalent in another, his own individual experience, especially the language he has grown up with, will influence how he perceives the word in the first place. Such a finding has a practical implication for translators. In translating a literary text, the translator often has to search for the "mot juste" so that he can represent the word not only denotatively but also affectively. Now, while he may find a word that matches the original to his own satisfaction, the word may still be off-key because his perceptions of the original word are not the same as the author's whose work he is translating. It is precisely these subtleties that distinguish a good translation of, say, a piece of poetry from a bad one. As we have stated earlier, the full range of possibilities in which such differences may be manifested, let alone their possible origins, are merely hinted 
at by the data we have been able to present here. Further investigations may uncover more of the general principles required to guide translators in this area. With regard to the origins of the individual differences, a more comprehensive individually-based approach is called for, perhaps using ethnographic methods, i.e., life histories and participant observation, to unravel the processes by which the connotative distinctions between languages are acquired.

\section{REFERENCES}

BYNNER, J. and P. COXHEAD (1979) : "Some problems in the analysis of semantic differential data", Human Relations, 32, 367-385.

CATTELL, R.B., H.W. EBER, and M.M. TAKSUOKA (1970) : Handbook for the Sixteen Personality Factor Questionnaire, Champaign (Illinois), Institute for Personality and Ability Testing.

Chambers Twentieth Century Dictionary, Edinburgh (Scotland), W. and R. Chambers, 1977.

CORMACK, R.M. (1971): "A review of classification", Journal of the Royal Statistical Society, Series A, 134, 321-367.

DILLER, K. C. (1970): "Compound" and "coordinate" bilingualism: A conceptual artifact, Word, 26, 254-261.

EARLE, M.J. (1967): "Bilingual semantic merging and an aspect of acculturation", Journal of Personality and Social Psychology, 6, 304-312.

ERWIN, S. and C.E. OSGOOD (1965): "Second language learning and bilingualism", in C.E. Osgood and T.A. Sebeok (Eds.), Psycholinguistics: A Survey of Theory and Research Problems, Bloomington, Indiana University Press.

EYSENCK, H.J. and S.B.G. EYSENCK (1969): Personality Structure and Measurement, London Routledge and Kegan Paul.

HALLWORTH, M.J. (1965): "Dimensions of personality and meaning", British Journal of Social and Clinical Psychology, 4, 161-168.

KISH, L. (1959): "Some statistical problems in research design", American Sociological Review, 24, 328-338.

KUUSINEN, J. (1969): "Affective and denotative structures of personality ratings", Journal of Personality and Social Psychology, 12, 181-188.

LAMBERT, W.E., J. HAVELKA and C. CROSBY (1958): "The influence of language acquisition contexts on bilingualism", Journal of Abnormal and Social Psychology, 56, 239-244.

MCKENNELL, A.C. and J.M. BYNNER (1969): "Self-images and smoking behaviour among school boys", British Journal of Education Psychology, 39, 27-39.

MIRON, M.S. and C.E. OSGOOD (1966): "Language behaviour; the multivariate structure of qualification", in R.B. Cattell (Ed.), Handbook of Multivariate Experimental Psychology, Chicago, Rand McNally.

OSGOOD, C.E., G.J. SUCI, and P.M. TANNENBAUM (1957) : The Measurement of Meaning, Urbana (Illinois), University of Illinois Press.

PAWLICK, K and R.B. CATTELL (1964): "Third-order factors in objective personality tests", British Journal of Psychology, 55, 1-18.

ROBERT, P. (1977) : Le Petit Robert, Paris, Société du Nouveau Littré.

ROMNEY, D. and J. BYNNER (1972): "Drug addicts as perceived by hospital staff", British Journal of Social and Clinical Psychology, $I, 20-34$.

SNEATH, P.H A and R.R. SOKAL (1973): Numerical Taxonomy, San Francisco, Freeman.

STAFFORD, K.R. and S.R. VAN KEWEN (1968) : "Semantic differential profiles as related to monolingual-bilingual types", Language and Speech, $11,167-170$.

TANAKA, Y. (1967): "Cross-cultural compatibility of the affective meaning systems (measured by means of multilingual semantic differentials)", Journal of Social Issues, $23,27-46$. 


\section{APPENDIX}

Technical Note on Cluster Analysis

The spacing measure used was based on Penrose's "size coefficient" (Sneath and Sokal, 1973, p. 170) and was derived from the original factor scores as follows.

Given the scores $E_{1}, E_{2}, F_{1}, F_{2}$ of one set of four concepts on one of the two factors $\mathrm{E}$ or $\mathrm{N}$, where $\mathrm{E}_{1}, \mathrm{E}_{2}$ are the scores for the English synonyms and $\mathrm{F}_{1}, \mathrm{~F}_{2}$ are the scores for the French synonyms, then the size of the space between synonyms within languages

$$
D_{w}^{2}=\left[\frac{\left|E_{1}-E_{2}\right|+\left|F_{1}-F_{2}\right|}{2}\right]^{2}
$$

and the size of the space between concepts and their translation-equivalents across languages

$$
D_{B}^{2}=\left[\frac{\left|E_{1}-F_{1}\right|+\left|E_{1}-F_{2}\right|+\left|E_{2}-F_{1}\right|+\left|E_{2}-F_{2}\right|}{4}\right]^{2}
$$

Hence, the size of the space between concepts and their translation-equivalents, corrected to take account of the space between synonyms.

$$
D_{C}^{2}=D_{B}^{2}-D_{W}^{2}
$$

Details of the computer programme can be found in the documentation for MIDAS compiled by D.J. Fox and K.E. Guire (1976) for the University of Michigan's Statistical Research Laboratory. 